\title{
UT Arlington Wins AMS Exemplary Program Award
}

\section{Allyn Jackson}

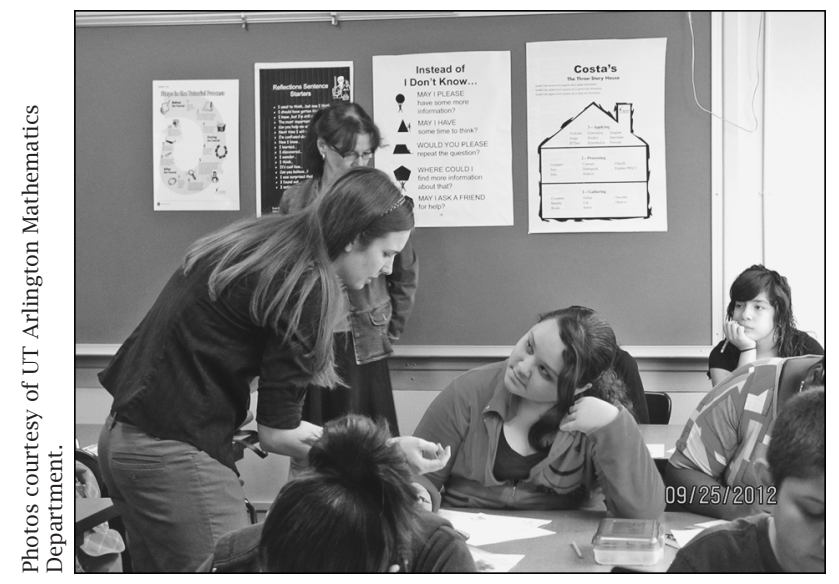

Ph.D. student and NSF GK-12 fellow Larrissa Owens helps middle school students, while math professor Minerva Cordero-Epperson looks on. Owens is a 4th year Ph.D. student working on modeling of wound healing. Cordero-Epperson, now Associate Dean of Science, directs the 5-year GK-12 program.

The University of Texas at Arlington is not elite. It's not the flagship campus of its university systemthat distinction goes to UT Austin. It's not as well known as some of its neighbors, like Rice University and Texas A\&M. It doesn't have huge resources, especially since the economic downturn. It's not an obvious place to find a stand-out mathematics department with a thriving graduate program. And yet that's just what the UT Arlington Department of Mathematics has become.

Over the past several years the department has transformed itself by making the growth and development of its graduate program its top priority. That goal led naturally to improvements in other areas-such as student mentoring, the undergraduate program, and outreach-as the department sought to develop a sufficient pool of well-prepared doctoral students. To support these activities, the department systematically

Allyn Jackson is senior writer and deputy editor of the Notices. Her email address is axy@ams . org.

DOI: http://dx.doi.org/10.1090/noti1008 pursued outside funding. As success built upon success, the faculty adopted a common vision of what the department could achieve and created a positive, can-do environment where teaching, research, mentoring, and service are all valued. For this outstanding transformation, the UTA Department of Mathematics has received the AMS Award for an Exemplary Program or Achievement by a Mathematics Department.

\section{Making the Case for Math}

Texas has three so-called "Tier 1" research universities: UT Austin, Rice, and Texas A\&M. The state has been aiming to increase the number of Tier 1 institutions, so in 2004, UT Arlington launched an initiative to move up to that level. While there is no precise definition of Tier 1 , the term generally refers to institutions with a high level of research, strong graduate programs, and substantial outside funding. UT Arlington set specific targets to work toward Tier 1 status, including producing two hundred Ph.D.'s each year and having annual research expenditures of US\$100 million. In 2005, with support from the state legislature, UTA was poised to invest in areas that could help it achieve these goals.

In such initiatives mathematics sometimes looks like a minor player compared to other areas of science and engineering, especially those that appear to have more research cachet and that bring in large grants. Jianping Zhu saw things differently. When he took the position as chair of the UTA mathematics department in 2005, he found a great deal of potential. What attracted him, he said, was the department's excellent reputation and its long-standing doctoral program, which was started more than forty years ago. Zhu knew some successful mathematicians who had gotten their Ph.D.'s at UTA, and he had known a former chair, the late George Fix, who left Carnegie Mellon University in the early 1990s to help build up the UTA department. UTA's expansion plans also made the position attractive for Zhu. He saw that in order to thrive the department had to align its mission with that of the university. "From that 
point of view, it's actually pretty easy to make the case" for mathematics, Zhu said.

He followed three main principles. First, mathematics is central to the university's teaching and research efforts. All UTA undergraduates are required to take mathematics courses, so how well the department delivers on its teaching responsibilities has a direct impact on the education mission of the university and on student retention and graduation. In addition, mathematics research underpins a broad range of interdisciplinary research in natural sciences, engineering, and social sciences. "To become a Tier 1 research university, UTA must build a strong mathematics department," Zhu said.

Second, mathematics is cost effective. "Mathematicians don't require labs,” Zhu said. "They just need pencil, paper, and a computer to do their jobs." He continually made the case to the administration that, compared to laboratory-based sciences, mathematics is much cheaper.

The third principle concerns outside funding. Mathematics research grants usually are not large. "But there are scholarship grants, both at the undergraduate and graduate level, that are quite substantial in size," Zhu said. Putting the focus on that type of grant allowed the department to dovetail two needs: attracting more and better students by offering scholarship and fellowships, and showing the university that mathematics could bring in substantial grant money.

\section{Small College Atmosphere}

Zhu left UTA in 2011 to become dean of the College of Graduate Studies at Cleveland State University, and Jianzhong Su took over as chair of the UTA mathematics department. Su has been at UTA for twenty-three years and has a good perspective on how the department has changed. Before 2005, Su said, "we were like every other department-we were all busy with our own research and working with our own students." What really changed the department, he said, was a newfound focus on improving mentoring and support for all graduate students. "We are a large state university of 34,000 students...but we want to create an atmosphere that is more like a small college, where the faculty and students connect," he said. Su was graduate director in 2005 when Tuncay Aktosun joined the UTA faculty. Sharing a strong interest in and dedication to students, the two began organizing student mentoring sessions. Up until then, the main time set aside for students and faculty to interact outside of class was for meetings to advise students about which courses to take. "We found that students need help, especially new students," Zhu noted. "They need advice, and they need encouragement when they run into problems."

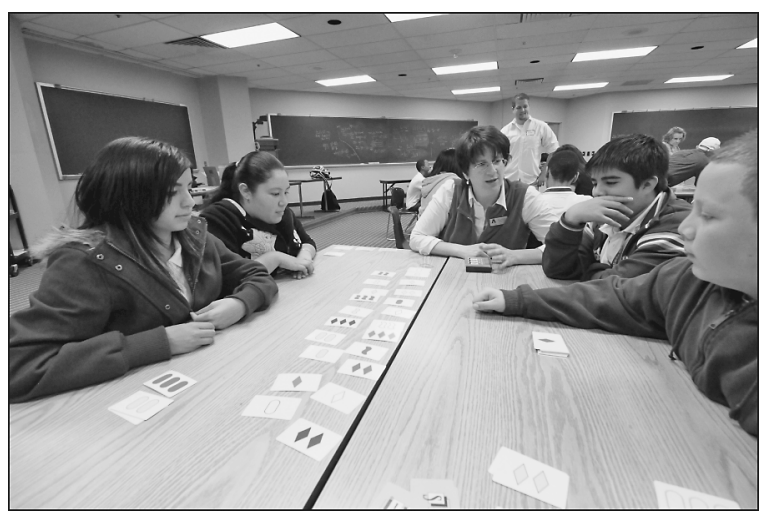

Creating a Ph.D. mathematician starts with students of young ages. Theresa Jorgensen, a winner of the University of Texas System Regents' Outstanding Teaching Award and co-PI of the NSF GK-12 program, works with middle school students on the mathematical game of Set during the UT Arlington Math Day.

When it became clear that students were really benefiting from the mentoring sessions, other faculty began to get involved. These sessions have helped the whole department become more close knit, fostering a welcoming atmosphere where students feel supported and problems are addressed early.

When Aktosun started at UTA, the graduate program was doing fairly well. It had twenty to twenty-five students, and in the previous decade had granted an average of three Ph.D.'s per year. But noting the low proportion of domestic students, Aktosun saw untapped potential. He led an effort to apply to the Department of Education program called Graduate Assistance in Areas of National Need, which supports departmental fellowships for graduate students who are U.S. citizens, nationals, or permanent residents. The department succeeded in getting its first GAANN grant, which ran from 2006 to 2010 and totaled US\$633,000; a new application brought a second GAANN grant of US\$653,000 for 2009-2012. The mathematics department was the first unit on the UTA campus to receive a GAANN grant. Since then several other UTA departments have successfully applied for GAANNs.

The GAANN fellowships prompted the mathematics department to revamp its recruiting methods. "In the old days, we were just waiting for students to apply," Su remarked. "But in the last ten years, we have been doing a lot more to reach out." The department established an annual GAANN Day, during which prospective students visit the department and interact with faculty and graduate students. Also invited are faculty from nearby institutions who might want to send their talented majors to the Ph.D. program 
at UTA, a tactic that Aktosun called "recruiting the mentors." Establishing a sense of trust with these mentors is one key to successful recruiting. "Those mentors are like the parents [of the students]," Aktosun said. They want to send their students into a supportive graduate program that values and nurtures students' talents. Many mentors have come to trust UTA in exactly that way. "We are going to support [the students], and we are going to graduate them," Aktosun said. "Their potential is going to be used in a maximal way." The efforts have paid off. In 2010 the department had fifty-two doctoral students, twenty-nine of whom were U.S. citizens or permanent residents, twenty were women, and eight were members of minority groups traditionally underrepresented in mathematics; efforts to increase these numbers have continued.

Much of what the department learned a lot about recruiting came from the National Alliance for Doctoral Studies in the Mathematical Sciences. The alliance aims to maximize educational and research opportunities for talented students from underrepresented groups. The UTA graduate program is now one of twenty-two alliance members that work with about one hundred eighty undergraduate mentors nationwide to ensure that students are placed in programs where they will thrive. As a regional leader in encouraging underrepresented groups in mathematics, the UTA department is now helping to organize a regional Gulf States Alliance that will work with the National Alliance to maximize opportunities for students who live in states around the Gulf of Mexico.

In addition to improving recruitment, the UTA department made a few key changes to better serve its graduate students. One small change made a big difference in the atmosphere: interspersing faculty and graduate student offices, which prompted many to leave their doors open more often and to chat more. The department revised the structure of the preliminary examinations to allow students to take the exams in an order better suited for academic progress. This change made the exam structure more student-friendly while maintaining the quality control the exams provide. There are now review sessions for the preliminary examinations, in which more-advanced graduate students help newer ones to prepare. The department offers many other opportunities for graduate students to act as role models, including through its various outreach programs. As a result, the graduate students feel a real sense of belonging and make substantial contributions to the department's overall success.

A new component of the graduate program is a professional development course in which graduate students learn basic career "survival skills" such as communicating effectively, both orally and in writing; working in a team setting; and applying for grants. "Part of the reason for the success of the doctoral program is that we provide good professional development, so the students have found good jobs," Zhu noted. "Our doctoral students find jobs in a variety of professions, from banking to insurance to actuarial science, to government jobs, to tenure-track faculty positions in colleges and universities."

\section{Success with Outside Funding}

In addition to GAANN, the department received from the National Science Foundation (NSF) a fiveyear GK-12 grant, which supports eight graduate fellows per year. The GK-12 program is a partnership of three groups-university faculty, graduate students, and schoolteachers - that aims to boost school student interest in science, technology, engineering, and mathematics. One GK-12 activity has graduate students explaining their research to the school kids. It's a big challenge. The graduate students spend a couple of weeks over the summer developing their presentations with the help of their faculty advisors and the schoolteachers. Su recalled the experience of one of his own graduate students, whose research concerned a diffusion equation. There was no point in writing down the equation for the 9th-graders, but maybe he could show them the solution, which is an exponential function? No, said the teacher, exponential functions do not arise until the 11th grade. The student finally came up with a way to explain what a diffusion equation is by likening it to a line of people with buckets passing a quantity of water down the line. "It's important for mathematics Ph.D. students to have the ability to communicate with society," Su remarked. "That way, they can make a bigger impact with their research." Because of the intensive collaboration involved, he noted, the GK-12 program "really bonds the faculty and the students together."

UTA faculty member Minerva Cordero-Epperson is the principal investigator on the US\$2.8 million GK-12 grant; coprincipal investigators have included Aktosun, Su, and Zhu, as well as three other UTA faculty members: James Epperson, Theresa Jorgensen, and Hristo Kojouharov. All have a strong commitment to teaching; Cordero, Epperson, and Jorgensen each received the Regents' Outstanding Teaching Award from the University of Texas System. Epperson directs the UTA Mathematics Teacher Preparation Academy, which has received about US\$1 million from the Texas Higher Education Coordinating Board. These are just a few of the UTA mathematics department faculty who have successfully pursued grant opportunities; since 2011, 80 percent of the faculty have had grants. 
While improving its doctoral program has been the department's top priority, it did not forget about its mathematics majors. To improve support for these students, the department successfully applied for two major grants from the NSF: an S-STEM (Scholarships in Science, Technology, Engineering, and Mathematics) grant of US $\$ 483,000$ for 2008 to 2012 and a UBM (Undergraduates in Biological and Mathematical Sciences) grant of US\$780,000 for 2008 to 2013. Both grants support scholarships, mentoring, and other activities designed to enrich the learning experience and enhance preparedness for the job market or graduate school. The department has also received grants from the National Research Experience for Undergraduates Program of the Mathematical Association of America, which supports REU programs aimed at students from underrepresented groups.

Grant money surely helps, but other zero-cost improvements have also made a difference. For example, the department gave the undergraduate student organization a bigger office where students could hang out and plan activities. This made them feel that "they truly have a home in the department," said Zhu. The department also includes math majors in as many graduate student activities as possible. The attention to the undergraduate program has yielded results: the number of mathematics majors jumped from around one hundred in 2005 to around three hundred today. "We would like to have more," Su said, noting that the job opportunities for math majors are good in the Dallas-Fort Worth region.

The department cultivates future math majors in programs such as the Mid-Cities Math Circle, headed by Dimitar Grantcharov, and an annual "Calculus Bowl" for high school students, run by Kojouharov. Every year the department collaborates with Riverside School, a local middle school, and the Rotary Club of Fort Worth to organize a "Math Camp": Three hundred 8th-graders and their teachers come to the UTA campus for half a day of activities designed to spark students' interest in mathematics. Over 90 percent of Riverside students are Hispanic, and most are poor. For many of them the UTA Math Camp marks their first time on a university campus. Aktosun said that when he looks at those 8th-graders, he thinks, "In six or seven years, they will be our math majors; in a decade, our doctoral students."

The UTA mathematics department is so good at everything it does it has become a testing ground for innovative programs on the campus. When there is talk of carrying out a pilot program, "the university says, 'Let math try it, and we'll see if it works,"' Su said. "We are energetic, we know what we are doing, and we make sure the program is carried out." Being the one that tries

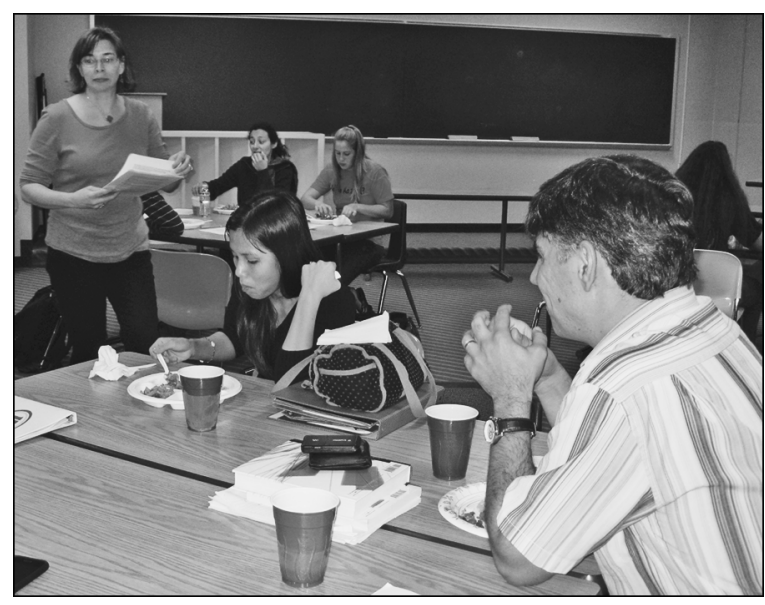

Mentoring of undergraduate students in the Math Department's S-STEM program, supported by the NSF. Math professors Ruth Gornet (standing) and Hristo Kojouharov (right) are at a SURGE working lunch meeting, where mentoring and math activities take place.

new, innovative programs gives the department an edge. "It's a way that we can make our department stand out from the crowd."

\section{A Horse, Not a Maverick}

When he first came to UTA, Zhu found that some faculty were trying to revise the departmental promotion policies so that for professors in areas of mathematics where job prospects for new Ph.D.'s are more limited than in other areas, the criterion of having Ph.D. students would not be part of promotion decisions. "The argument was, we can't get students," Zhu recalled. Today, with the growth in the graduate program, such worries have disappeared, along with much of the turfprotection mentality that produced them in the first place. "Many of the divisions and frictions that were really obvious years ago are now less obvious," he noted. "We all realize we have our differences...but we see that if we work together, we build a stronger program, and it benefits everyone in the department."

The motto of UT Arlington is "be a maverick". Aktosun is not fond of this motto and its implication that accomplishment comes only to those who go it alone. The real work is done not by mavericks, but by horses, he said. "We were able to create a good environment where everyone contributes, and everyone in the end benefits because their neighborhood becomes a nice neighborhood to live in-the department becomes a desirable place to be," he said. "Those incentives that benefit the community are what drives the horses rather than the incentives that drive the maverick." The moral: “Don’t be a maverick. Be a horse." 